\title{
CONHECIMENTO E SOCIEDADE: UMA ABORDAGEM SOBRE A DIVERSIDADE DOS SABERES E SEUS CONTEXTOS
}

\author{
Valdir Jose Morigi \\ Luis Fernando Herbert Massoni \\ Ketlen Stueber \\ Arthur Walber Viana \\ Universidade Federal do Rio Grande do Sul (UFRGS) \\ Brasil
}

\section{RESUMO}

Apresenta a disciplina 'Conhecimento e Sociedade', do Departamento de Ciências da Informação da Universidade Federal do Rio Grande do Sul. É oferecida como matéria obrigatória nos currículos dos cursos de graduação em Arquivologia e Museologia e como eletiva para os cursos de Biblioteconomia, Jornalismo, Publicidade e Propaganda, Relações Públicas e História da Arte. Reflete sobre a importância de disciplinas que possibilitem e reforcem o diálogo entre os diferentes saberes produzidos socialmente, tendo como princípios norteadores valores de respeito ao 'outro', diversidade cultural e cidadania. Os conteúdos trabalhados na disciplina partem da história e das diferentes vertentes que constituem o conhecimento social, por meio de uma abordagem inter e multidisciplinar, através das dimensões históricas, culturais, políticas, psicossociais e éticas que envolvem a construção dos diferentes saberes sociais. Relata os objetivos, a metodologia, o referencial teórico e as experiências de aprendizagem utilizadas na disciplina. Conclui que há a necessidade de disciplinas que reflitam de forma crítica as formas canônicas e excludentes de entender 0 mundo a partir de classificações e de hierarquizações que possibilitaram a hegemonia do conhecimento ocidental sobre os saberes locais e periféricos. Em contraponto, uma perspectiva dialógica que considere a ecologia dos diversos saberes e seus contextos possibilita a compreensão da sua complexidade ao mesmo tempo em que é capaz de religar os diferentes saberes: Ciência, Arte, Mito e Religião e seus imaginários.

Palavras-Chave: Diversidade; Conhecimento Social; Conhecimento e Sociedade.

\section{KNOWLEDGE AND SOCIETY: AN APPROACH ON THE DIVERSITY OF KNOWLEDGE AND ITS CONTEXTS}

\begin{abstract}
The article introduces the discipline 'Knowledge and Society', from the Information Sciences Department of the Federal University of Rio Grande do Sul, Brazil. Its offered for Archivology and Museology students as compulsory and as an elective subject for Library Science, Journalism, Advertising and Public Relations students. It reflects on the importance of disciplines that enable and reinforce the dialogue between the different socially produced knowledge, having as guiding principles values of respect for the other, cultural diversity and citizenship. The contents presented in the discipline depart from the history and the different aspects that constitute social knowledge through an inter-multidisciplinary approach, going across historical, cultural, political, psychosocial and ethical dimensions that involve the construction of different social knowledge.
\end{abstract}




\section{Rebecin \\ EDUCAÇÃO em CIÊNCIA da INFORMAÇÃO}

It reports the objectives, the methodology, the theoretical background and the learning experiences used in the discipline. It concludes that there is a need for disciplines that critically reflect the canonical and excluding ways of understanding the world based on categorizations, classifications and hierarchies that have allowed the hegemony of Western knowledge over local and peripheral lore. In contrast, a dialogical perspective that considers the ecology of diverse knowledge and its contexts allows the comprehension of its own complexity, while being able to reconnect different knowledge such as Science, Art, Mith, Religion and its imaginaries.

Keywords: Diversity; Social Knowledge; Knowledge and Society.

\section{INTRODUÇÃO}

Vivemos tempos marcados pelo avanço do conservadorismo, não apenas no Brasil, com a queda de um governo democraticamente eleito e caracterizado por conquistas sociais, mas também em nível global, com o fortalecimento de discursos extremistas pouco abertos às diferentes formas de se compreender e se estar no mundo. A incapacidade de dialogar e entender o ponto de vista do 'outro' é consequência desse contexto, evidenciado pela falta de respeito e intolerância para com certos grupos sociais. O despreparo na compreensão e apreciação das diferenças entre os sujeitos e grupos decorre da falta de reflexão sobre as origens das diferentes culturas, formas de vida e os múltiplos conhecimentos que compõem nossa sociedade.

Com o intuito de refletir sobre estas questões, o presente artigo relata a experiência da disciplina 'Conhecimento e Sociedade', ofertada pelo Departamento de Ciências da Informação (DCl) da Faculdade de Biblioteconomia e Comunicação (FABICO) da Universidade Federal do Rio Grande do Sul (UFRGS). A FABICO/UFRGS é uma das poucas faculdades brasileiras a oferecer cursos de Ciência da Informação (Cl) e Comunicação Social no mesmo centro de ensino (Arquivologia, Biblioteconomia, Jornalismo, Museologia, Publicidade e Propaganda e Relações Públicas). Essa interação social e epistêmica entre os campos evidencia tensões e propicia interessantes diálogos e debates.

Os profissionais da informação e da comunicação precisam estar conscientes de seu papel e comprometidos na luta em prol do respeito à diversidade e às diferentes formas de viver e de conhecer. A falta 


\section{Rebecin \\ EDUCAÇÃ̃O em CIÊNCIA da INFORMAÇÃO}

de reflexão crítica desses profissionais perante a realidade social em parte é devido ao caráter tecnicista e pouco flexível dos currículos dos cursos, que formam profissionais capacitados, porém pouco reflexivos. Diante desse fato, surgem as questões: De que modo os conteúdos de uma disciplina podem auxiliar na compreensão da diversidade cultural e instigar os futuros profissionais a refletirem sobre o exercício do seu ofício? Como a percepção dos diferentes saberes e seus contextos sociais de produção possibilitam o diálogo, o respeito à diversidade cultural e à cidadania?

A perspectiva crítica e teórica dos conteúdos trabalhados na disciplina 'Conhecimento e Sociedade' parte da história social do conhecimento no mundo Ocidental e destaca, sobretudo, a hegemonia do positivismo, responsável por hierarquizar e praticamente extinguir os conhecimentos alternativos. A cultura, os contextos sociais e 0 encontro com o 'outro' possibilitam diálogos entre diferentes percepções, afirmam a necessidade de renovar e substituir as monoculturas do conhecimento por uma ecologia dos saberes, onde seja possível a coexistência não-hierárquica de diferentes compreensões sobre 0 mundo. Os objetivos, metodologia, referencial teórico e a perspectiva da disciplina 'Conhecimento e Sociedade' destacam a interdisciplinaridade e a relação com as habilidades e competências dos cursos de graduação em informação e comunicação, especialmente em Arquivologia, Biblioteconomia e Museologia, para intensificar a formação crítica e reflexiva dos futuros profissionais da $\mathrm{Cl}$.

Além da crítica à construção e classificação hierárquica do conhecimento, a disciplina coloca os diferentes saberes no nível de igualdade epistêmica, abrindo o diálogo entre os saberes científicos e a tradição. Nesse contexto, se incluem os saberes do senso comum e os ambientais. Ela vai ao encontro das diretrizes do Ministério da Educação (BRASIL, 2012), que estabelecem um conjunto de critérios para o ensino de disciplinas voltadas à educação ambiental e/ou relacionadas com 0 meio ambiente. O Artigo 14 (BRASIL, 2012) afirma que a educação ambiental deve enfatizar a natureza como fonte de vida, a dimensão 
socioambiental, cooperativa e de justiça social a fim de respeitar e promover a diversidade étnica, racial e de gênero. Deve afirmar-se em contraposição às relações de exploração e dominação para, deste modo, inserir-se nos processos de educação e dialogar com todas as áreas e níveis de ensino a partir de abordagens integradas e transversais que busquem 0 aprofundamento crítico-reflexivo com os estudos científicos, socioeconômicos, políticos e históricos.

\section{HISTÓRIA SOCIAL DO CONHECIMENTO, DIÁLOGO E DIVERSIDADE DOS SABERES}

A disciplina 'Conhecimento e Sociedade' apresenta múltiplos saberes. $O$ Quadro 1 dispõe as distintas abordagens por meio de autoras e autores e os principais conceitos estudados. De modo geral, os textos possuem um alto nível de complexidade, especialmente devido ao ser caráter epistemológico. Além de leitura prévia, o momento da aula é aberto para a participação de alunas e alunos com perguntas e comentários sobre os temas abordados. conteúdo é composto por perspectivas históricas, cognitivas, sociais e epistêmicas.

Quadro 1: Disciplina 'Conhecimento e Sociedade': principais autores e conceitos

\begin{tabular}{|l|l|}
\hline \multicolumn{1}{|c|}{ Autores } & \multicolumn{1}{c|}{ Principais Conceitos } \\
\hline Burke, Peter (2003; 2012) & Conhecimento Social. \\
\hline Jovchelovitch, Sandra (2004; 2008) & Polifasia cognitiva e o saber do 'outro'. \\
\hline Maffesoli, Michel (1998) & Razão sensível e senso comum. \\
\hline Caune, Jean (2014) & Cultura científica e técnica. \\
\hline Jacob, Christian (2012) & Lugares do saber. \\
\hline Gomez Muñoz, Maritza (2003) & Saber indígena. \\
\hline Felice, Massimo di (2014) & Sociedade em rede. \\
\hline Almeida, Maria da Conceição de (2010a; 2010b) & $\begin{array}{l}\text { Ecologia do conhecimento; A postura de um } \\
\text { intelectual. }\end{array}$ \\
\hline Coelho, Eduardo Prado (2004) & O novo intelectual. \\
\hline Morin, Edgar (2005; 2007) & Paradigma da complexidade. \\
\hline
\end{tabular}

Fonte: Elaboração própria - 2017.

Peter Burke é professor titular da Universidade de Cambridge, onde ministra aulas sobre História da Cultura. Seus escritos sobre a história social do conhecimento introduzem o conteúdo da disciplina 'Conhecimento e Sociedade'. Especificamente, as obras de Burke (2003; 2012) 


\section{Rebecin \\ EDUCAÇÃO em CIÊNCIA da INFORMAÇÃO}

contribuem para o conhecimento dos seguintes temas: história do conhecimento; lugares de conhecimento; consolidação do conhecimento; conhecimento social; ofícios do saber; instituições do saber; classificação do conhecimento; e cronologias do conhecimento.

A partir deste conjunto de temas, adquire-se uma noção aprofundada sobre o conceito de conhecimento social, desde suas nuances históricas até sua construção e consolidação. Todo este processo encontra-se permeado de fatores políticos e de relações de poder, ou seja, a partir de Burke (2003; 2012) compreende-se como ocorreram as classificações que derivaram na construção hierárquica do conhecimento, marcada principalmente pela corrente filosófica positivista atuante e hegemônica até os dias atuais, que se refletem na formação do pensamento científico e na forma de fazer ciência dentro e fora das instituições de ensino.

Sandra Jovchelovitch é professora da London School of Economics, no Reino Unido, onde dirige o Instituto de Psicologia Social e - Programa de Mestrado em
Psicologia Social e Cultural. A contribuição da Psicologia Social no debate sobre as diferentes formas de saber diz respeito aos contextos sociais em que são produzidos os saberes: as culturas e as comunidades. Essa perspectiva percebe os saberes sociais como uma modalidade de representação. Eles são resultados das interações que se estabelecem entre os diferentes sujeitos sociais no espaço e no tempo. A disciplina 'Conhecimento e Sociedade' busca compreender, através do pensamento de Jovchelovitch (2004; 2008), como os saberes são construídos a partir do conjunto de contextos socioculturais.

Jovchelovitch (2008) aprofunda a discussão acerca do conhecimento, entrelaçando-o com a importância das estruturas culturais pertencentes aos grupos e as distintas sociedades e, desse modo, qualifica a importância da tolerância e da alteridade, expressas através da necessidade de inclusão da perspectiva do 'outro', o seu reconhecimento e o quanto isso é legítimo. A autora defende uma postura dialógica no momento da comunicação, ou seja, aberta ao diálogo entre os indivíduos. Os 


\section{Rebecin \\ EDUCAÇÃO em CIÊNCIA da INFORMAÇÃO}

sujeitos constroem a si mesmos, constituem e expandem seus saberes por meio das interações com o 'outro' e seu conjunto de conhecimentos socialmente adquirido.

A autora enfatiza duas coisas que envolvem a natureza das relações intersubjetivas entre o 'eu' e 'outro'. A tomada de perspectiva do 'outro': isso implica em reconhecer os diferentes lugares de onde os sujeitos falam e se posicionam e o seu reconhecimento. É desses lugares sociais que os sujeitos sabem o que sabem, o que os torna singulares. A inclusão da perspectiva do 'outro' possibilita a coexistência de diferentes formas de saber da vida social (polifasia cognitiva), que tendem à hibridização.

Outro autor que contribui para o debate é Michel Maffesoli, professor de sociologia na Universidade de Sorbone, na França, e diretor do Centro de Estudos do Atual e do Cotidiano, sendo uma referência em pesquisas sobre imaginário social na área da Sociologia e da Comunicação. A partir do conceito de senso comum, que denomina de razão sensível, Maffesoli (1998) desconstrói o pensamento positivista e descartiano que divide e isola o conhecimento.
Para o autor, a divisão entre razão e emoção apenas distancia 0 ser humano dos processos de conhecimento de si, dos outros e do mundo à sua volta.

$\mathrm{Na}$ perspectiva do autor, a ciência é um saber enraizado na vida e no cotidiano, demanda de experiências variadas, pois é da ordem do social e do coletivo, segundo Maffesoli (1998). O senso comum é ressignificado pelo autor, pois atua com intensidade no âmbito sensível; logo, é a base para o desenvolvimento dos saberes e do conhecimento científico. Deste modo, Maffesoli (1998) defende uma dialética entre o racional e o afetivo, o inteligível e $o$ sensível, pois é por meio desta interação que os processos de aprendizagem são absorvidos de maneira completa.

Jean Caune é professor emérito da Universidade de Stendhal de Grenoble, na França. Suas pesquisas abordam questões relacionadas à medição cultural, meios de comunicação e democratização do conhecimento por meio da apropriação e uso das tecnologias de informação e comunicação. Neste sentido, Caune (2014) levanta reflexões acerca da 


\section{Rebecin \\ EDUCAÇÃO em CIÊNCIA da INFORMAÇÃO}

ciência e das tecnologias na contemporaneidade. Para além das aplicações industriais e da instrumentalização das tecnologias para o mercado, a união entre ciência e tecnologia repercute no cotidiano e na vida social. Há, portanto, uma nova cultura gerada e estabelecida a partir da interação com a ciência e a tecnologia.

A partir deste cenário, Caune (2014) propõe o conceito de cultura científica e técnica (CST), um misto de discursos e saberes entrecruzados e baseados na epistemologia, filosofia, história das ciências, sociologia da inovação, comunicação e informação, entre outros. A cultura científica e técnica é um fenômeno híbrido socialmente construído e possui como missão participar na construção da democracia tecnológica a partir da produção coletiva de aprendizagens em que cidadãos, cientistas, políticos e outros atores sociais deliberam em conjunto.

Christian Jacob dirige a Escola de Altos Estudos em Ciências Sociais na França. Suas pesquisas buscam compreender a história da antiguidade por meio de textos e documentos produzidos por povos e culturas antepassadas. Ou seja, o pesquisador desenvolve estudos sobre 0 funcionamento e a forma das tradições do saber. Para Jacob (2014), os saberes são um conjunto de sentidos atribuídos pela sociedade ao mundo que os cerca e estes saberes são materializados por meio de discursos, símbolos e artefatos.

Os lugares do saber podem ser dinâmicos, estáveis e/ou provisórios, pois se encontram em vários suportes: documentos, objetos, pessoas, animais, plantas, etc. Os lugares do saber assumem, para o autor, quatro âmbitos distintos: comunitário; erudito; de validação social; e de historicidade. O saber habita as pessoas, grupos e culturas; logo, seu primeiro plano é a comunidade. O segundo é o saber erudito, pois é encontrado em manuais, gráficos e discursos. O terceiro âmbito do saber é a validação social, pois está presente nas práticas de ensino-aprendizagem e produção escrita. O âmbito da historicidade é o da contextualização cultural, em que o espaço da organização do conhecimento é designado por meio dos diferentes lugares, épocas e modos originários do saber. Estes lugares são definidos a partir das 


\section{Rebecin \\ EDUCAÇÃO em CIÊNCIA da INFORMAÇÃO}

práticas de desempenho, transmissão e circulação social.

Maritza Gomez Muñoz é consultora da Universidade Pedagógica Nacional do México. Seus estudos fundamentam-se na cultura dos povos indígenas e nos processos de aquisição de conhecimento em suas práticas culturais cotidianas. Assim, o saber indígena é uma das referências práticas dos conteúdos abordados ao longo da disciplina. A escolha por esse saber fundamentase, principalmente, na reconexão do ser humano com a natureza percebida nesse saber, bem como pela importância dos povos indígenas na construção da história social do Brasil.

A ênfase nas experiências de aprendizagem comunitária mostra a relação e a conexão intrínseca existente entre o saber indígena e o lugar e o enraizamento com o meio ambiente, descritos por Gomez Munõz (2003), através da transmissão das informações e dos saberes a partir da valorização dos ritos, dos mitos e dos símbolos que auxiliam na conformação da identidade cultural étnica dos povos indígenas. O saber indígena origina-se e se reconhece nas experiências e nas práticas comunitárias a partir de ações denominadas pela autora como: "saber ser, saber estar e saber dar uso" Para além de conceitos verbalizados, o saber indígena se fundamenta na memória coletiva, na tradição oral, nas relações de respeito à natureza e suas forças (míticas e energéticas), nas relações de afeto e de cuidado compartilhado por adultos e crianças e pelas práticas de cultivo. O saber indígena insere 0 conhecimento numa harmoniosa pedagogia comunitária.

Em outro contexto de referência da produção dos saberes ligados ao contexto contemporâneo, entra no debate Massimo di Felice, professor da Escola de Comunicação e Artes da Universidade de São Paulo. Seus estudos partem da sociologia, antropologia e comunicação para compreender as redes complexas geradas a partir das tecnologias de informação e comunicação. A sociedade em rede tem alterado as práticas e os significados de comunicar por meio de novas relações entre a linguagem, o sentir a partir dos usos e das apropriações das tecnologias.

Uma nova estrutura comunicativa, mais interativa, 


\section{Rebecin \\ EDUCAÇÃO em CIÊNCIA da INFORMAÇÃO}

reconfigura a ideia de lugar a partir das mídias sociais. Segundo Felice (2014), essa nova configuração comunicativa desenvolve 0 pensamento em rede e estimula a participação e interação simbólica, evidenciando como se configura 0 conhecimento em rede. Essa nova ação comunicativa permite 0 acesso mais veloz a mais informações, o que possibilita a multiplicação das visões de mundo. Tal condição implica na geração de novos valores e em uma nova ética participativa podendo, inclusive, ressignificar o conceito de democracia.

Maria da Conceição de Almeida é professora dos programas em Educação e em Ciências Sociais da Universidade Federal do Rio Grande do Norte. Desenvolve pesquisas a partir das teorias do pensamento complexo e as dinâmicas de ensinoaprendizagem. Para a autora, a ciência é uma expressão da cultura (dentre as várias existentes), ou seja, é uma forma de diálogo.

A ressignificação do saber científico pode ser instituída através da ecologia dos conhecimentos científicos, segundo Almeida (2010b). Este processo se dá a partir da universalidade do saber e a inclusão dos sentidos, pela hibridização do pensamento e pela relação respeitosa entre as teorias científicas, a mitologia das culturas e os saberes tradicionais. Reconhecer os saberes da tradição é afirmá-los como pertinentes, inseridos em um contexto. O pensamento aberto reconfigura também a postura do intelectual, que, em sintonia com a ecologia dos conhecimentos, desenvolve práticas investigativas múltiplas e flexíveis. O mundo pode ser entendido a partir de experiências subjetivas e pela aproximação e o diálogo entre os saberes. Trata-se, sobretudo, de uma atitude ética capaz de dialogar com diferentes formas de encarar o mundo em direção de uma "ecologia das ideias".

O intelectual é mediador de conhecimento científico e tradicional. De acordo com Almeida (2010a), é preciso assumir com acuidade a arte de refletir, de tratar e transformar as informações em conhecimentos; eis a face primordial dos intelectuais. Estes prezam pela diversidade da cultura e dos saberes, resistem às padronizações científicas, reconhecem culturas milenares e fazem dialogar com os diferentes conhecimentos 
produzidos socialmente. $\mathrm{O}$ verdadeiro intelectual reconhece que não é o único portador de cultura científica, tampouco o tradutor privilegiado das concepções de mundos e fenômenos.

As diferentes formas de perceber 0 mundo correspondem a uma matriz diversificada da condição humana.

\section{Eduardo Prado Coelho foi} professor associado da Faculdade de Ciências Sociais e Humanas da Universidade Nova Lisboa, em Portugal. Desenvolveu seus estudos na área da filologia, literatura, cultura e comunicação. Para 0 autor, os intelectuais geram e têm responsabilidade sob $\mathrm{o}$ uso $\mathrm{e}$ a manipulação da matéria simbólica. Ele tece críticas, também, a universidades voltadas unicamente a servir o mercado.

Segundo Coelho (2004), o novo intelectual é aquele que forma competências. Em outras palavras, é aquele que deve oferecer pontes entre os diversos códigos e traduzir as linguagens entre as culturas. Além disso, o intelectual precisa ainda desenvolver estratégias mediáticas não demagógicas para disseminar o saber e intervir na vida pública através das competências informacionais e comunicativas. Deste modo, o uso das tecnologias pode servir como ferramenta de legitimação intelectual. O saber deve ser autônomo e guiado para a liberdade.

A disciplina finaliza introduzindo o pensamento complexo a partir da abordagem proposta por Edgar Morin, antropólogo, sociólogo e filósofo francês, sendo um dos grandes pensadores contemporâneos. É conhecido por desenvolver as teorias do pensamento complexo e sua produção é essencial para o conteúdo da disciplina 'Conhecimento e Sociedade'. O paradigma complexo suspende a perspectiva cartesiana, que divide o ser humano entre corpo e espírito e separa o pensamento racional do emocional. Segundo Morin (2007), o pensamento desenvolvido a partir de pressupostos disjuntivos tende ao reducionismo e ao simplismo.

A visão complexa parte de um senso de solidariedade e caráter multidimensional; une as ciências humanas, científicas e sensitivas; considera as incertezas, pois a complexidade é dialógica e hologramática (a parte está no todo e o todo está na parte). Segundo Morin (2007), o pensamento complexo é 


\section{Rebecin \\ EDUCAÇÃO em CIÊNCIA da INFORMAÇÃO}

múltiplo e considera os sistemas de saber a partir de perspectivas disjuntivas, conjuntivas, implicativas e de causa e efeito, pois busca unir o múltiplo e o uno. O conhecimento, a partir desta perspectiva, pode ser analisado em completude.

O paradigma cartesiano impôs uma forma hegemônica de conhecer, de entender e de agir sobre o mundo, caracterizado pela sua fragmentação, e consolidou as ciências modernas dos Séculos XVII, XVIII e XIX. Entretanto, a partir da primeira metade do Século $X X$, mostra-se insuficiente para compreender a complexidade dos fenômenos contemporâneos. Assim, o paradigma da complexidade, com uma proposta epistemológica aberta e não simplificadora, propõe a religação dos saberes, apostando em uma postura transdisciplinar nos modos se ver e de produzir os saberes.

\section{CONHECIMENTO E SOCIEDADE:} UMA INTERDISCIPLINA?

A disciplina 'Conhecimento e Sociedade' foi criada em 2005 junto ao $\mathrm{DCl}$ da $\mathrm{FABICO/UFRGS.} \mathrm{É} \mathrm{oferecida}$ semestralmente, sendo obrigatória para os cursos de Arquivologia (2ำ semestre) e Museologia (3ํㅗㄴ semestre) e eletiva para os cursos de Biblioteconomia ${ }^{1}$, Jornalismo, Relações Públicas, Publicidade e Propaganda e História da Arte. A disciplina, fundamentalmente teórica e de cunho epistemológico, possui carga horária de 60 horas (4 créditos).

Estudantes da área da comunicação e da informação necessitam conhecer as diferentes esferas da cultura, dos saberes e discursos, pois sua atuação profissional recorre da interação diversificada com distintos públicos e demandas. No campo da $\mathrm{Cl}$ (Arquivologia, Biblioteconomia e Museologia), é preciso que as habilidades e competências de seus profissionais abranjam as múltiplas facetas do conhecimento produzido na sociedade, pois compete a estes a organização, a gestão e a disseminação de diferentes documentos e conteúdos. Para isso, a disciplina 'Conhecimento e Sociedade' busca desenvolver um olhar sensível e reflexivo sobre as condições sociais em que a informação e o conhecimento são produzidos, reconhecidos e valorizados, a partir de suas especificidades. Desse modo, ela 
aborda a natureza social do conhecimento e sua produção, a interdisciplinaridade, as formas e origens de saberes locais, considerando o conhecimento e sua relação com 0 paradigma da complexidade. Os objetivos da disciplina são:

a) Proporcionar uma visão de conjunto sobre a natureza e história social do conhecimento, enfatizando as condições sociais da produção do conhecimento, os diferentes tipos de saberes e sua relação com a sociedade;

b) Identificar os pressupostos teóricos das condições sociais da produção do conhecimento e os contextos do saber;

c) Identificar as características e os diferentes tipos de saber produzidos socialmente;

d) Discutir as formas do fazer científico e a produção do conhecimento social e cultural;

e) Auxiliar na tradução das necessidades de indivíduos, grupos e comunidades nas respectivas áreas de atuação;

f) Desenvolver raciocínio crítico em relação aos fatos, acontecimentos e as formas de produção científica; g) Refletir sobre as formas de produção do conhecimento e seu vínculo com a realidade social;

h) Responder a demandas de informação determinadas pelas transformações que caracterizam o mundo contemporâneo;

i) Auxiliar na interpretação das relações entre homem, cultura e natureza, no contexto temporal e espacial.

Com relação à metodologia, a disciplina faz uso de exposição oral e dialogada, seminários a partir de trabalhos em grupo, palestras e vídeos. As atividades de avaliação incluem a participação nos seminários, uma prova escrita e finaliza com a elaboração, em grupo, de uma fotonovela, através da qual os estudantes, a partir dos conteúdos lidos e discutidos nas aulas ao longo do semestre, desenvolvem uma história na qual aplicam os principais conceitos abordados.

Os seminários em grupo estruturam a disciplina ao longo do semestre, pois é a partir das apresentações dos alunos que são desenvolvidas as discussões em torno dos textos com a mediação do professor. Os estudantes devem ler 


\section{Rebecin \\ EDUCAÇÃO em CIÊNCIA da INFORMAÇÃO}

todos os textos de apoio elencados e distribuídos no início do semestre, mas são livres para escolherem sobre qual texto desejam apresentar o seminário - cada seminário é apresentado por um grupo formado por três a cinco alunos, aproximadamente. Após cada apresentação, é reproduzido um vídeo (geralmente entrevistas ou documentários com no máximo 30 minutos) que aborde questões pertinentes aos conceitos e temas apresentados no seminário e, por fim, inicia-se a discussão com a participação de todos os estudantes. Além de auxiliar na apropriação dos conceitos e temas abordados, os seminários também objetivam proporcionar um momento de trabalho em equipe, fundamental para uma disciplina que se propõe a discutir o respeito à diversidade de saberes e o diálogo enquanto prática inerente à construção de conhecimentos.

A primeira avaliação realizada é uma prova individual, aplicada na metade do semestre, através da qual se percebe a apropriação e a reflexão a respeito dos temas abordados até aquele momento. A prova é dissertativa e composta por cinco a seis questões amplas, cada uma delas geralmente pertinente a um conceito ou tema trabalhado durante os encontros presenciais. Embora a prova seja um método de avaliação geralmente rígido, o objetivo de sua aplicação na disciplina não é medir conhecimentos ou incentivar os estudantes a decorarem conteúdos. Ao contrário, é valorizada a reflexão e a crítica a respeito de cada assunto, momento em que são aceitas menções aos textos, vídeos, discussões em sala de aula, além de opiniões e relatos pessoais.

Por fim, a segunda avaliação é a elaboração e apresentação (geralmente com o uso do programa Power Point) de uma fotonovela. Essa atividade é um momento de grande interação entre os membros dos grupos (geralmente, entre quatro e seis estudantes) e, através dela, os alunos exercitam a criatividade e demonstram diferentes apropriações dos conceitos e temas abordados. $\mathrm{Na}$ maioria das fotonovelas, são os próprios estudantes que interpretam as personagens, mas algumas fazem uso de fantoches, montagens, ursos, desenhos ou qualquer outro recurso, de acordo com a criatividade de cada grupo. $\mathrm{O}$ enredo das histórias 


\section{Rebecin \\ EDUCAÇÃO em CIÊNCIA da INFORMAÇÃO}

apresentadas é livre, mas deve estar relacionado às temáticas discutidas ao longo do semestre.

Algumas fotonovelas desenvolvidas até então abordaram questões como: as tensões entre diferentes saberes (popular versus erudito, tradicional versus científico); o conhecimento como fruto das experiências dos sujeitos; preconceitos, discriminação e estereótipos; relações entre conhecimento e sexo, gênero, nacionalidade, etc. As fotonovelas são apresentadas pelos grupos em sala de aula e, posteriormente, discutidas entre os estudantes com a mediação do professor. Nesse momento, os estudantes relatam como foi a experiência de realizar a fotonovela e se manifestam a respeito da disciplina e dos métodos pedagógicos utilizados pelo professor. Essas atividades encerram a disciplina.

Entretanto, tratá-la como uma disciplina reforça os padrões de entendimento que reduzem o mundo, as suas relações e sua complexidade. Se assim fosse, ela seria apenas mais uma entre outras no conjunto de disciplinas que compõem as grades curriculares dos cursos de graduação.
Ao tomar como estudo 0 conhecimento social e sua problematização e refletir criticamente sobre as múltiplas dimensões que o envolvem, aciona e mobiliza diversos conceitos vindos de lugares ou campos distintos (Antropologia, Filosofia, História, Psicologia Social, Sociologia, Comunicação, Ciência da Informação, etc.). O diálogo interdisciplinar se faz presente, pois abre a disciplina para outros campos, tornando-a, na prática, como uma interdisciplina. Isso possibilita que se faça um maior número de conexões possíveis entre os diferentes saberes sociais que circulam na sociedade, ampliando a visão de mundo dos educandos e dos educadores.

\section{CONSIDERAÇÕES FINAIS}

'Conhecimento e Sociedade' aborda a história social do conhecimento de forma reflexiva e crítica, questiona os padrões instituídos que envolvem a produção, a comunicação e a apropriação dos saberes a partir das pedagogias de ensino e aprendizagem por meio da ressignificação dos modos de produção, aquisição e de apropriação 
do conhecimento. Nesse processo, não desconsidera a subjetividade que permeia as nossas experiências. $O$ conhecimento é resultado das interações que se estabelecem entre os diferentes sujeitos sociais no espaço e no tempo. Ao contextualizar o conhecimento, critica as formas canônicas e excludentes de entender o mundo a partir de classificações e hierarquizações que possibilitaram a hegemonia do conhecimento ocidental sobre os saberes locais e periféricos. A perspectiva dialógica que considera a ecologia dos diversos saberes e seus contextos possibilita a compreensão da sua complexidade, ao mesmo tempo em que é capaz de religar os diferentes saberes: ciência, arte, mito e religião e seus imaginários.

Para além dos pressupostos teóricos, 'Conhecimento e Sociedade' se caracteriza na prática como uma interdisciplinar, pois estimula, através de conteúdos interdisciplinares, um amplo leque de conexões que aproximam os conceitos debatidos com o mundo vivido no cotidiano, ultrapassando as barreiras do espaço da sala de aula. Os textos das autoras e dos autores lidos e os conceitos trabalhados são relacionados com a vida diária a partir das vivências sociais dos estudantes, que futuramente poderão se valer de tais conhecimentos e aprendizados para fundamentar suas ações profissionais e pessoais. O propósito é enriquecer as experiências de aprendizagem dos estudantes, fomentando discussões que propiciem formas diferentes de olhar o mundo, o ser humano, as coisas e seu próprio conhecimento, entendo-o como resultado de suas vivências e da sua cultura.

Para tanto, a metodologia adotada foi planejada de modo a romper com alguns "sensos comuns" criados pela academia sobre a superioridade do conhecimento científico face aos demais conhecimentos que circulam no mundo social. Essa visão fragmentada distancia quem produz os conhecimentos dos seus produtos, colocando barreiras e hierarquias entre produtores e conhecedores. $\mathrm{Na}$ sala de aula, isso se repercute naquele que "sabe" e o que "nãosabe", afastando docente-discente. Ao estimular a comunicação através dos debates e das trocas de ideias entre os estudantes na sala de aula, 


\section{Rebecin \\ EDUCAÇÃO em CIÊNCIA da INFORMAÇÃO}

eles se tornam também protagonistas da construção do seu próprio conhecimento. As metodologias de ensino-aprendizagem adotadas também possibilitam as interações entre os acadêmicos por meio dos trabalhos em grupo e da participação nos debates. As fotonovelas, por sua vez, exploram a capacidade criativa dos estudantes e estimulam o trabalho coletivo e o aprendizado em grupo, pois a produção do conhecimento envolve a criação.

\section{REFERÊNCIAS}

ALMEIDA, M. da C. de. A dupla face de um mesmo intelectual. In:

\section{Complexidade, saberes}

científicos e saberes da

tradição. São Paulo: Livraria da Física, 2010a. p.43-68.

ALMEIDA, M. da C. de. Para uma ecologia dos conhecimentos. In:

científicos e saberes da Complexidade, saberes tradição. São Paulo: Livraria da Física, 2010b. p.139-163.

BRASIL. Ministério da Educação. Resolução no 2, de 15 de junho de 2012. Brasília, 2012. Disponível em: $<$ http://portal.mec.gov.br/index.php?opt ion=com_docman\&view=download\&ali as $=10988-\mathrm{rcp} 002-12$

pdf\&category slug=maio-2012-

pdf\&Itemid=30192 >. Acesso em: 13 mar. 2017.
BURKE, P. Uma história social do conhecimento: de Gutemberg a Diderot. Rio de Janeiro: Zahar, 2003.

BURKE, P. Cronologias do conhecimento. In: Uma

\section{história social do}

conhecimento II: da Enciclopédia a Wikipédia. Rio de Janeiro: Zahar, 2012.

CAUNE, J. A cultura científica e técnica na era da informação, da comunicação e do conhecimento. In:

\section{Cultura e}

comunicação: convergências teóricas e lugares de mediação. São Paulo: Editora Unesp, 2014. p.91-107.

COELHO, E. P. Novas configurações da função do intelectual. In: MARGATO, I.; GOMES, R. C. (Org.). O papel do intelectual hoje. Belo Horizonte: Editora da UFMG, 2004. p.13-22.

FELICE, M. di. Network society: da esfera pública para a conectividade. In: MARCHIORI, M. Sociedade, comunidade e redes. São Caetano do Sul: Difusão; Editora Senac, 2014. p.91-110.

GOMES MOÑOZ, M. Saber indígena e meio ambiente: experiências de aprendizagem. In: LEFF, $\mathrm{H}$. (Coord.). A complexidade ambiental. São Paulo: Cortez, 2003.

JACOB, C. Retorno aos lugares de saber. Revista UFMG, Belo Horizonte, v.19, n.1-2, p.206-227, jan./dez. 2012. Disponível em:

<https://seer.ufmg.br/index.php/revista daufmg/article/view/1828/1322>.

Acesso em: 13 mar. 2017. 


\section{Rebecin \\ EDUCAÇÃ̃O em CIÊNCIA da INFORMAÇÃO}

JOVCHELOVITCH, S. Psicologia social: saber, comunidade e cultura. Psicologia e Sociedade, Rio de Janeiro, v.16, n.2, p.20-31, maio/ago. 2004.Disponível em: <http://dx.doi.org/10.1590/S010271822004000200004>. Acesso em: 13 mar. 2017.

JOVCHELOVITCH, S. Ao encontro do saber do outro. In: Os contextos do saber: representações, comunidade e cultura. Petrópolis:

Vozes, 2008.

MAFFESOLI, M. Elogio da razão sensível. Petrópolis: Vozes, 1998. p.161-197.

MORIN, E. O paradigma complexo. In: Introdução ao

pensamento complexo. 3.ed. Porto

Alegre: Sulina, 2007.

\section{NOTAS}

1 'Conhecimento e Sociedade' era disciplina obrigatória do Curso de Biblioteconomia, tornando-se eletiva após reforma curricular realizada em 2010.
Valdir José Morigi

Universidade Federal do Rio Grande do Sul (UFRGS)

Professor Titular do Programa de Pós-

Graduação em Comunicação e Informação

E-Mail: valdir.morigi@gmail.com Brasil

Luis Fernando Herbert Massoni Universidade Federal do Rio Grande do Sul (UFRGS)

Doutorando e Mestre em

Comunicação e Informação. Bolsista CAPES.

E-Mail:

luisfernandomassoni@gmail.com

Brasil

Ketlen Stueber

Universidade Federal do Rio Grande do Sul (UFRGS)

Doutoranda em Educação em

Ciências: Química da Vida e Saúde

E-Mail: ketistueber@hotmail.com

Brasil

\section{Arthur Walber Viana}

Universidade Federal do Rio Grande do Sul (UFRGS)

Mestrando em Comunicação e Informação. Bolsista CAPES

E-Mail: arthurwalber@hotmail.com Brasil 